\title{
THE EFFECT OF PANTOTHENIC ACID DEFICIENCY ON GASTRIC SECRETION AND MOTILITY
}

\author{
By GEORGE H. M. THORNTON, WILLIAM B. BEAN, AND ROBERT E. HODGES \\ (From the Metabolism Ward of the Department of Medicine, College of Medicine and Uni- \\ versity Hospitals, State University of Iowa, Iowa City, Ia.)
}

(Submitted for publication January 13, 1955 ; accepted March 16, 1955)

Reports of animal experiments and results of preliminary studies by Bean and Hodges (1) in man indicated that the metabolic effects of pantothenic acid deficiency in human subjects would be widespread and profound. Such was the case (2). Insofar as it was possible to predict the metabolic changes in this experiment it seemed likely that one feature would be a suppression of adrenal cortical function and that this might lead to a secondary reduction of gastric secretion. On the other hand, following Lipmann's (3) demonstration that pantothenic acid is the active principle of coenzyme $\mathrm{A}$, it has been shown that many metabolic processes involve acetylation reactions in which coenzyme A is essential (4). This led to the hypothesis that coenzyme A might play a fundamental part in the metabolism of parietal cells and that pantothenic acid deficiency would, therefore, have a direct inhibitory effect on their production of hydrochloric acid. These were the theoretical considerations which led to the special study of gastric function during pantothenic acid deficiency in the hope of obtaining information of physiological and possibly therapeutic interest. This paper reports the results of these studies which were undertaken concurrently with those reported by Bean, Hodges, and Daum (2).

\section{MATERIALS AND METHODS}

The subjects of the experiment were three normal young adult men who had no previous history of gastrointestinal disease. During the experiment there were five different dietary periods. Since a palatable diet deficient in pantothenic acid cannot be prepared from natural foods, a synthetic liquid formula was prepared and this was administered directly into the stomach through a plastic tube $5 \mathrm{~mm}$. in diameter. This formula, which contained an adequate supply of all essential food factors, including pantothenic acid, was given for an initial control period of 12 days. For a second period of 25 days the same formula was used but pantothenic acid was omitted and omega-methylpantothenic acid, a metabolic antagonist to pantothenic acid, was substituted.
In the third phase of the experiment both pantothenic acid and the antagonist were administered with the object of correcting the deficiency. After six days of this regimen the expected improvement in the manifestations of deficiency had not occurred and it became necessary to allow a general diet by mouth supplemented by pantothenic acid and other vitamins. At this stage there were manifestations of insufficiency of the adrenal cortex and cortisone was administered in small daily doses for four days (2). Three days after terminating cortisone therapy tube feeding was resumed and continued for nine days as a final control period. The original formula containing pantothenic acid, but not the antagonist, was administered during this final period.

Three tests were selected to compare gastric secretory and motor function during the development of deficiency with the normal function during the initial control period and during the final recovery period. These tests were a modification of the serial test meal devised by Hunt and Spurrell $(5,6)$, the secretory response to histamine, and the secretory response to insulin. For all these tests plastic tubes $5 \mathrm{~mm}$. in diameter and having one terminal and four lateral holes were used. Saliva was collected throughout each test by an oral catheter attached to an electric suction pump.

Test meals were considered essential to the investigation because they provide a physiological stimulus to gastric secretion and supply information about the emptying pattern of the stomach. Neither basal secretion nor histamine nor insulin tests provide direct chemical and mechanical stimulation of the stomach mucosa and wall. However, since the concentration of hydrochloric acid in gastric contents is dependent both on the rate of secretion and the rate of emptying of the stomach, fractional methods are of little value where quantitative information about secretion is required (7). In the technique devised by Hunt a series of meals of constant volume and composition and containing phenol red are completely withdrawn after different intervals of time on different days. Complete emptying of the stomach at the beginning and end of each meal is ensured by lavage with a known volume of distilled water. From the results of a series of meals composite graphs of the secretion and emptying during the whole digestive phase can be constructed. Hunt has shown that viscosity is unimportant in a test meal and that the pectin in his original formula is unnecessary. He has found that a meal consisting of $750 \mathrm{ml}$. of sucrose solution containing $75 \mathrm{gm}$. sucrose and approximately $60 \mathrm{mgm}$. phenol red per liter 
is satisfactory (8). It has been confirmed in this laboratory in eight normal subjects and patients with peptic ulcers that a meal of this composition will give remarkably constant results from day to day with regard to both secretion and motility. By estimating the concentration of phenol red in the original meal and in the stomach contents on each occasion it is possible to calculate the volume of the original meal remaining in the stomach. By assuming that the concentration of dye leaving the stomach through the pylorus during each interval is equal to the mean of the initial and final concentrations, the volume of gastric contents passing the pylorus during each time interval can be calculated. Penner, Hollander, and Saltzman (9) have shown that phenol red is suitable for this purpose as it is neither altered nor absorbed by the stomach. By a similar technique if the concentrations of hydrochloric acid, total chloride and pepsin in the gastric contents are estimated in each of the series of meals, the quantity of these substances which has passed the pylorus in between the time of withdrawal of each meal can be calculated. Since the volume of gastric contents at each time is known the amount of each constituent secreted at various stages of the digestive period can be estimated. In a series of 19 normal subjects Hunt found that the gastric secretory and emptying pattern of each individual remained remarkably constant from day to day. He also showed that if the volume of the original meal remaining in the stomach (calculated from the volume of gastric contents and the concentration of phenol red) is plotted against time for a series of meals an exponential curve is obtained.

In this laboratory exponential curves of gastric emptying have been obtained in 17 experiments on 15 normal subjects and patients with peptic ulcer, using a meal containing either pectin and sucrose $35 \mathrm{gm}$. per liter or sucrose $75 \mathrm{gm}$. per liter without pectin. The technique was, therefore, considered suitable for the demonstration of the effect of pantothenic acid deficiency on gastric motility. Any alteration of the emptying pattern during deficiency might be expected to alter the exponential curve obtained for each subject during the control period.

The results of the studies of gastric secretion in response to the test meals, to histamine and to insulin have been expressed as volumes of parietal and non-parietal component of gastric juice. These volumes may be calculated from the amount of hydrochloric acid and total chloride secreted during a given period by using a formula evolved by Hunt (10) from Hollander's (11) concept of two component secretion of gastric juice in dogs, and from Ihre's (12) figures for the composition of pure gastric juice in man. This method has the advantage of taking into account neutralization of hydrochloric acid by the alkaline component of gastric secretion.

In the present experiment the volume of gastric juice secreted changed to such a degree that construction of a composite graph for the volumes of parietal and nonparietal component was not possible. These volumes were therefore calculated for each individual meal from time zero to the time of withdrawal. Since gastric secretion is generally rapid and constant for the first 30 minutes after ingestion of the meal, this interval was selected for the comparison of test meal data obtained at different phases of the experiment. Where the actual time of withdrawal of the meal was close to 30 minutes this forms a sound method of comparison. Normal gastric secretion has been found to become slower after 30 minutes and there is no way in which meals of longer duration can be compared with those of 30 minutes when the values for each are calculated from time zero, instead of being incorporated in a serial graph. Meals of longer duration were included in the present experiment so that data on gastric emptying could be obtained, and so that any rise in secretory rate at a late stage in the digestive period would not be overlooked. The result of each of these meals was plotted on a graph of time against volume of gastric juice and a straight line was drawn from this point to time zero volume zero. The volume was read from the point at which this straight line crossed the line representing 30 minutes. It is realized that this method gives an approximate estimate only of the actual secretion at 30 minutes but since the figures obtained were not inconsistent with those obtained when the actual duration of the meal was 30 minutes, they have been included in the graphs of the results. This method would reflect any gross changes in secretion during the latter part of the digestive phase from one period of the experiment to another. Where the actual time of withdrawal was less than 30 minutes the same method of expressing the results was used. Since gastric secretion generally remains constant in rate for the first 30 minutes the method is probably more accurate in this instance. If some slowing of secretory rate did occur before 30 minutes this method would tend to produce unduly high readings for 30 -minute secretion. The pepsin secretion was treated in the same way, graphs being drawn to determine the estimated total pepsin secretion at 30 minutes.

In order to determine the response of the parietal cells to direct chemical stimulation the volume of gastric juice secreted in response to the subcutaneous injection of histamine was measured during the initial control period, during the deficient diet and during the final control period. Wangensteen's apparatus was used to collect gastric secretion by continuous suction for $30 \mathrm{~min}$ utes before and 90 minutes after histamine. In addition, manual suction with a syringe was used at intervals of 30 minutes to check the patency of the tube. Blockage, when it occurred, was cleared by injecting small quantities of air. In view of the role pantothenic acid is believed to play in the metabolism of histamine (4) and the reduction of histaminase in the alimentary canal in adrenal insufficiency, (13) small doses (0.5 or $1.0 \mathrm{mgm}$.) of histamine phosphate were used. In addition each test was preceded by an injection of $2 \mathrm{ml}$. of the antihistamine, Thenfadil@, given intramuscularly, 30 minutes before the histamine dose to prevent untoward reactions. From the volume of gastric juice collected and the concentration of hydrochloric acid, total chloride and pepsin, the total amount of these constituents secreted in response to his- 
tamine was calculated. Using the same formula as in the serial test meals, these figures were converted into volumes of parietal and non-parietal components of gastric juice.

The gastric response to insulin was included in the investigation since this provides an indication of the sensitivity of the receptor-conductor mechanism for neurogenic stimuli to gastric secretion. It may thus serve to differentiate factors acting directly on the parietal cells from those acting on the psychic or reflex secretion of gastric juice. Since pantothenic acid deficiency suppresses adrenal cortical function in animals it was expected that the subjects of the experiment would develop some hypersensitivity to insulin. Small doses (5 or 10 units) of insulin were, therefore, used and these were given subcutaneously instead of intravenously. This made it necessary to collect gastric juice for a period of 150 minutes after insulin instead of 60 or 90 minutes. The technique of collection of gastric juice was the same as in the histamine tests, the insulin injection being preceded by collection of basal secretion for 30 minutes. Finger-tip blood samples were collected for blood sugar estimation once before insulin and at intervals of 30 minutes thereafter. The lowest reading of blood sugar was usually obtained at 60 minutes and occasionally at 90 minutes after insulin. The average fall of blood sugar was $36 \mathrm{mgm}$. per $100 \mathrm{ml}$. and on only two occasions was the fall less than $30 \mathrm{mgm}$. per $100 \mathrm{ml}$. A level of $50 \mathrm{mgm}$. per $100 \mathrm{ml}$. in venous blood is generally considered a satisfactory hypoglycemia. As the concentration of sugar in capillary blood is approximately $10 \mathrm{mgm}$. per $100 \mathrm{ml}$. higher than in venous blood, and as the capillary blood sugar level fell to $60 \mathrm{mgm}$. per $100 \mathrm{ml}$. or less in every test in this experiment, the hypoglycemia induced by the method used was considered adequate. The volumes of parietal component and non-parietal component and the quantity of pepsin secreted in response to hypoglycemia were calculated in the same way as in the histamine tests and the test meals.

The hydrochloric acid concentration in all specimens was determined by electrometric titration against $0.1 \mathrm{~N}$ sodium hydroxide with $\mathrm{pH} 6.5$ as the end-point (12), the sucrose solution used in the test meals having been adjusted to $\mathrm{pH} 6.5$ before administration. Phenol red does not have a sufficiently sharp end-point for use as the titration indicator, but its presence in the test meal specimens obscures Topfer's reagent and phenolphthalein.

Total chloride was also estimated by electrometric titration against $0.5 \mathrm{~N}$ silver nitrate solution using a silver-silver chloride electrode (12). This method is convenient, accurate and not affected by the presence of phenol red in the specimens.

Pepsin concentrations were estimated by the method of Bucher, Grossman, and Ivy (14). The substrate was prepared from commercial dried bovine hemoglobin powder (15). Anson's (16) curve was used to convert the results to pepsin units.

\section{RESULTS}

These are expressed graphically as volumes of parietal and non-parietal component and quantity of pepsin secreted in response to equal stimuli at different stages of the experiment. Figures 1, 2, and 3 show the results obtained in each of the three subjects. The whole shaded area represents the total volume of gastric juice, the dark shaded area shows the volume of parietal component, and the light shaded area shows the volume of nonparietal component.

The first graph in each figure shows the secretory response to the test meals. Above the results of each test the time of withdrawal of the meal is shown. In all three subjects at least one meal in each control period is comparable in duration with a meal or meals during the second and third periods when the symptoms of deficiency were present. In many instances the duration of the test meals was sufficiently near to 30 minutes to justify direct comparison. This applies to meals $1,6,8,9$, and 10 in subject M. C. (Figure 1 ); to meals $1,5,6,8,9$, and 10 in the subject $L$. N. (Figure 2); to meals $1,5,8$, and 9 in subject E. D. (Figure 3). On the basis of these meals alone it can be seen that in the subjects M. C. and L. N. (Figures 1 and 2) there was a profound fall in the gastric secretion, both of parietal and non-parietal components, during the period when the pantothenic acid deficient diet was being administered, with recovery during the final control period. The estimated 30-minute volumes of secretion derived from the meals of less than 30 minutes are probably valid also, since these were all during the deficient period and the method tends to produce a value above the actual $30-\mathrm{min}$ ute secretion. The figures obtained from the meals of more than 30 minutes' duration are considered to show that no significant gastric secretory response occurred during the later stages of the digestive period. The subject E. D. (Figure 3) shows a slight but much less significant fall during the period on the deficient diet. None of the three subjects showed a significant fall in the secretion of pepsin in response to a test meal, though the response to histamine and insulin is severely affected.

In the second graph of Figures 1, 2, and 3 the secretory response to histamine is indicated. The 


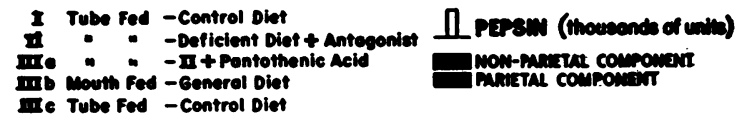

n.

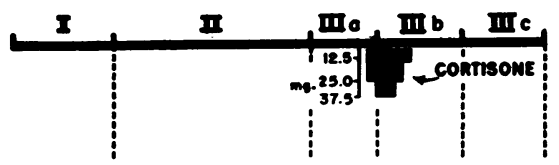

SLAML TEST MEAL (vol. Gostric Juice in $\mathrm{ml}$ )

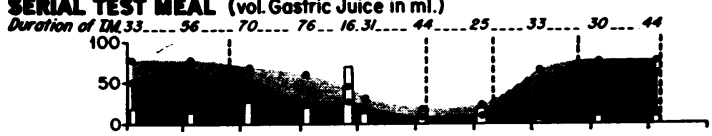

HiSTAMINE TEST (vol. Gastric Juice in $\mathrm{ml}$ )

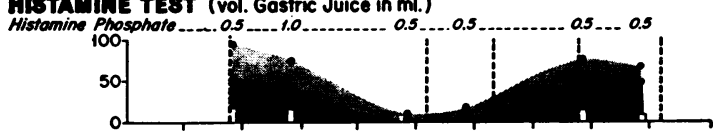

INSULUN TEST (rol. Gostric Juice in $\mathrm{ml}$.)

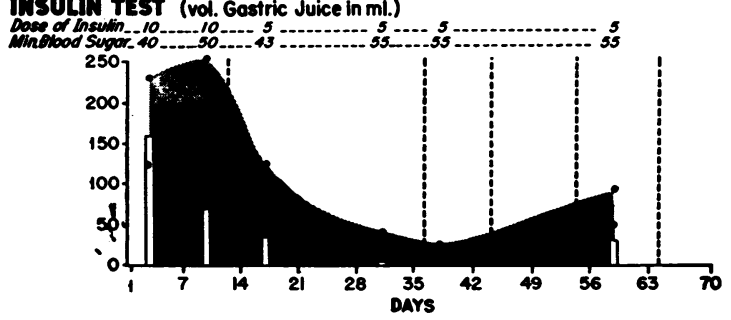

FIGURE 1
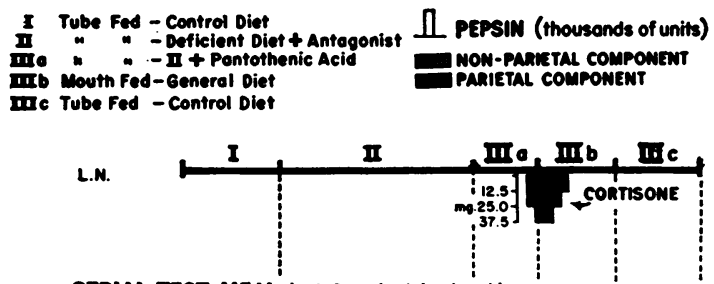

EThlNL TEST MEAL (vol. Gostric Juice in $\mathrm{ml}$. ) $30 \quad 32 \quad 30 \quad 48$

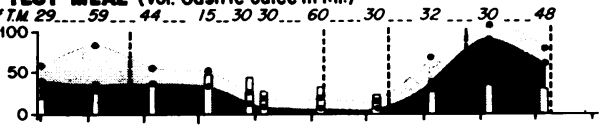

HISTAMINE TEST (vol. Gostric Juice in ml.)
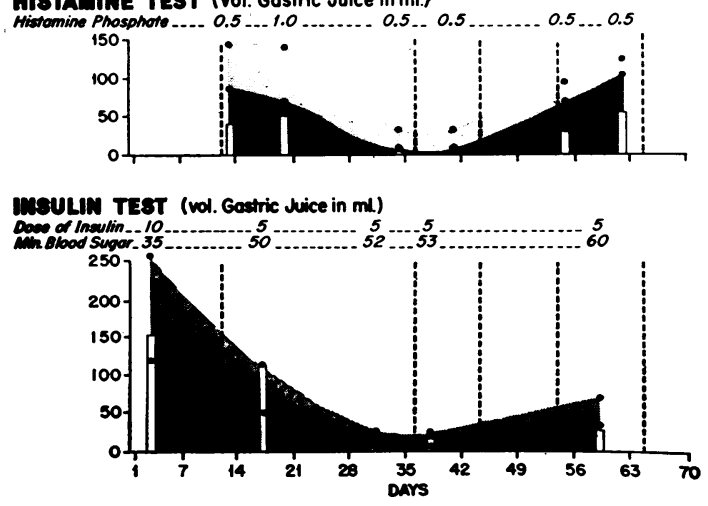

FIGURE 2

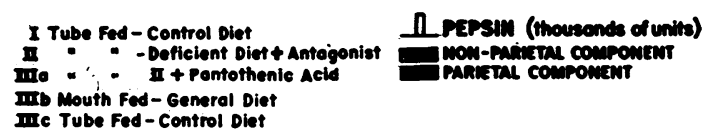

IIIC Tube Fed - Control Diet

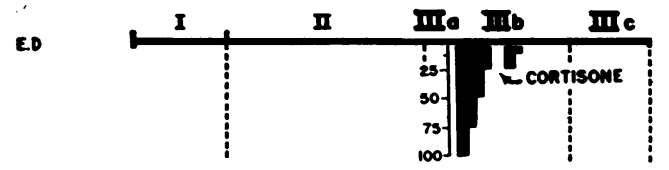

SERLAL TEST MEAL (vol. Gostric Juice in ml.)
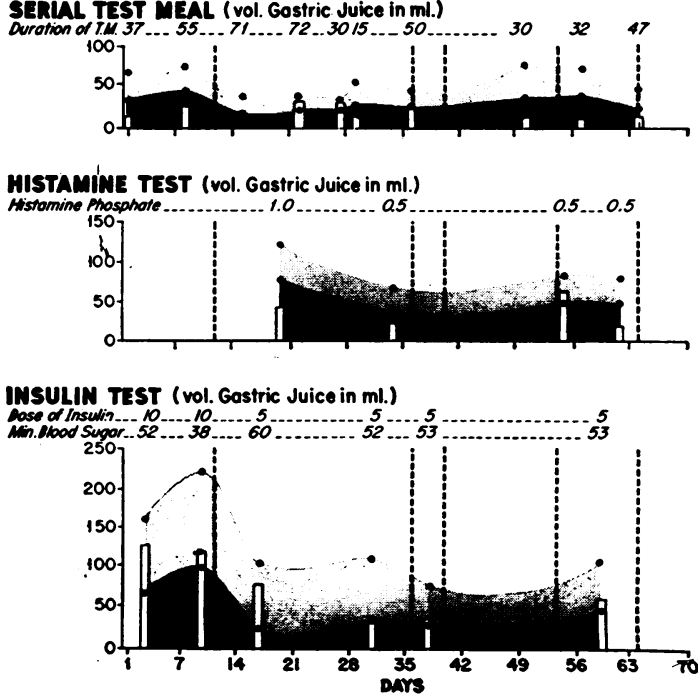

Figure 3

Figs. 1, 2, and 3. The Gastric Secretory Changes dering the Development of Pantothenic Acid Deficiency in the Slbjects M. C., L. N., and E. D.

The figures for the serial test meals show the estimated secretion at 30 minutes. Those for the histamine tests and insulin tests show the actual secretion during 90 and 150 minutes, respectively, after the test dose.

dose of histamine phosphate in mgm. is indicated above each test. Subjects M. C. (Figure 1) and L. N. (Figure 2) again show a striking fall in secretory response both of parietal and non-parietal component and of pepsin during the induction of pantothenic acid deficiency, with recovery during the final control period. The subject E. D. shows no significant change since the dose of histamine was greater in the first test than in the other three tests and there is no appreciable rise during recovery. The first histamine test in this subject was not obtained until seven days after beginning the deficient diet because of an attack of pharyngitis which made retention of a tube for 120 minutes impossible.

The third graph in each figure shows the secretory response to subcutaneous insulin. The dose of insulin and the lowest capillary blood sugar 
reading obtained are indicated above the results of each test. As might be expected when there is a marked fall in response to histamine there is also a fall in response to hypoglycemia in subject M. C. (Figure 1) and L. N. (Figure 2). The subject E. D. (Figure 3) shows a definite though less marked fall in his gastric response to hypoglycemia.

The test meal results were used to determine the effect of pantothenic acid deficiency on gastric motility. The number of meals obtained during each phase of the experiment was not sufficient to prepare separate graphs for the initial and final control periods and for the period of the deficient diet. However, the logarithms of the volumes of the meals remaining in the stomach were plotted against time for each subject throughout the experiment. The results are shown in Figures 4,5 , and 6 . In spite of gross changes in the volume of gastric juice secreted into the stomach the same exponential emptying pattern is retained by the subjects M. C. (Figure 4) and L. N. (Figure 5) throughout the experiment. The discrepant volumes found at 71 and 72 minutes in the subject E. D. (Figure 6) coincided with the pharyngitis already mentioned. His psychological reaction to the discomfort of being subjected to a test meal under these circumstances may explain the delay in gastric emptying (17). If they are excluded from the graph he also appears to have retained the same exponential emptying pattern.

\section{DISCUSSION}

The results of this experiment suggest that an adequate intake of pantothenic acid is essential to

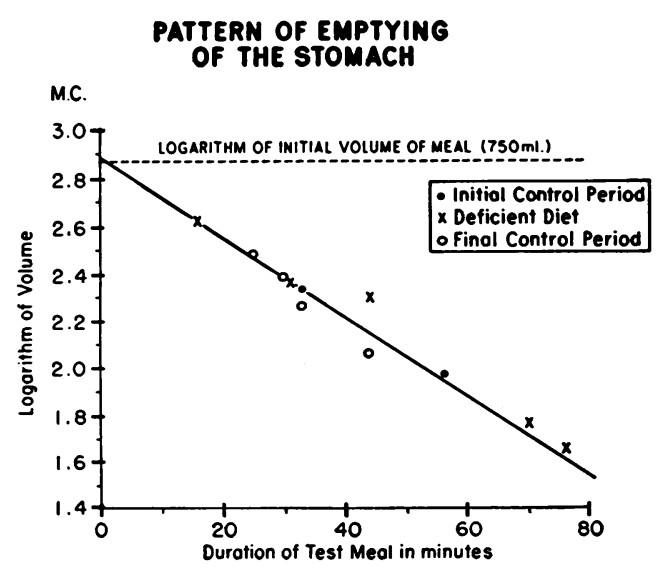

Figure 4

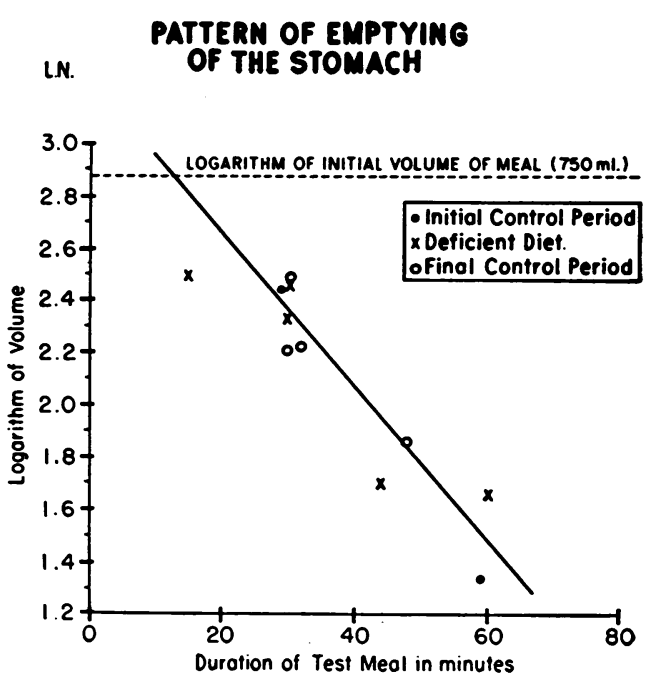

FIGURE 5

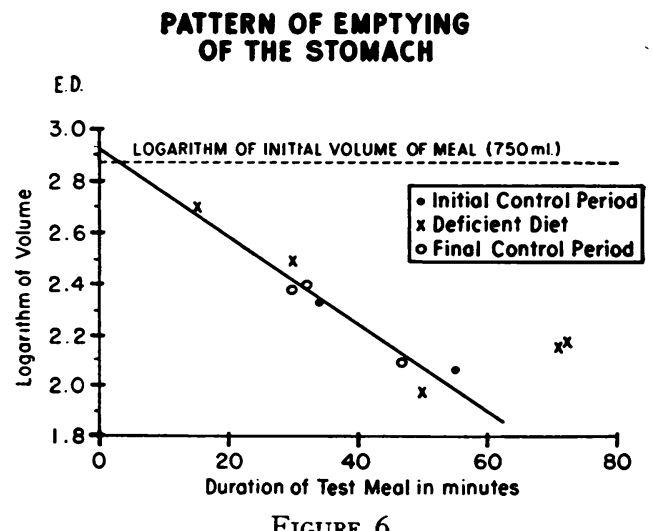

Figs. 4, 5, and 6. Logarithms of the Volumes of the Test Meal Remaining in the Stomach at Various Time Intervals after Ingestion Plotted against Time of Withdrawal for the Subjects M. C., L. N., AND E. D.

Each graph includes results obtained during the initial and final control periods as well as during the period of pantothenic acid deficiency.

normal gastric secretory function, but not to normal motility. The conditions of the experiment were abnormal in that the three subjects were receiving a synthetic diet directly into the stomach instead of a natural diet by mouth. There is no report in the literature on the effect of prolonged tube feeding on gastric secretion but it is common experience that the use of a milk drip, in the treatment of peptic ulcer, causes a temporary neutralization of acid in the stomach rather than any suppression of secretion. If the results obtained were 
caused by tube feeding alone some fall of secretion should have become apparent during the initial control period of 12 days and improvement of gastric function during the final control period would be most unlikely. In addition, the pepsin secretion in response to the test meals would be expected to undergo suppression to an extent similar to the other constituents of gastric juice. It is believed, therefore, that pantothenic acid deficiency was in fact responsible for the secretory changes. Though there are many reports (4) of the effects of pantothenic acid deficiency on other tissue in animal experiments, there are no reports of the effects on the stomach of man or animals.

Pantothenic acid deficiency might bring about a depression of secretion of gastric juice by two possible mechanisms. Since coenzyme A is essential to the formation of cortisone by the adrenal cortex in rats (18) and since the subjects of the experiment showed evidence of adrenal cortical dysfunction, $(1,2)$, it is possible that the effects were due to a deficient supply of cortisone. Since it was necessary to administer cortisone and restore vitamins to the diet simultaneously, because of severe symptoms, it is not possible to say which factor was responsible for restoring normal secretion. The diminished hydrochloric acid secretion commonly found in Addison's disease is in keeping with such a mechanism. The absence of a fall in pepsin secretion in the test meals in the present experiment is inconsistent with the finding of Spiro, Reinfenstein, and Gray (19) that uropepsin is absent from the urine of patients with Addison's disease and could be restored by giving cortisone. There is, however, insufficient evidence to establish whether or not the diminished gastric secretion was mediated through the adrenal cortex.

Alternatively coenzyme A might be essential to the metabolic processes whereby the parietal cells secrete hydrochloric acid. The "electron-cycle" mechanism described by Crane, Davies, and Longmuir (20) postulates the enzyme substrate system oxaloacetate $\underset{-2 \mathrm{H}}{\stackrel{+2 \mathrm{H}}{\rightleftharpoons}} \mathrm{L}$-malate to account for the transfer of hydrogen atoms across the pericanalicular zone of the parietal cells. Coenzyme A presumably plays a part in this mechanism. Deficiency of pantothenic acid could theoretically block the mechanism of secretion at this point, if the electron-cycle mechanism is the true process by which hydrochloric acid is produced. Since the precise mechanism of hydrochloric acid secretion and the precise metabolic functions of pantothenic acid have not been established, any theory as to the relationship between the two must, at present, remain purely speculative. The results of the present experiment merely show that such a relationship does exist. Further work is now being undertaken with the object of investigating the means by which pantothenic acid deficiency inhibits gastric secretion.

The results of the experiment do not suggest a reason for the relatively minor effect on the gastric secretion in one of the three subjects (E. D.). In this particular subject the central nervous system manifestations of deficiency and evidence of insufficiency of the adrenal cortex were more severe than in the other two subjects. This may be a manifestation of the variations observed in many deficiency states where a group of individuals are all affected by the same deficiency. Individual subjects of the present experiment showed considerable variation in the degree and rate of change in the system or tissue predominantly involved (2).

\section{SLMMARY AND CONCLUSIONS}

1. Pantothenic acid deficiency was induced in a group of three normal human volunteers, by diet and the administration of a metabolic antagonist.

2. Two of three subjects developed severe depression of gastric secretion which returned to normal after the experiment had been terminated.

3. The changes affected the volume of parietal and non-parietal components secreted in response to a meal, to histamine and to insulin.

4. Pepsin secretion in response to insulin and histamine was also diminished but pepsin response to a meal was unaffected.

5. It is postulated that the parietal cells were depleted of an essential metabolic factor, possibly coenzyme A. The diminished secretion may, however, have been an indirect result of depression of function of the adrenal cortex.

6. There was no significant change in gastric motility as a result of pantothenic acid deficiency. 


\section{ACKNOWLEDGMENT}

The authors wish to acknowledge with gratitude the technical assistance of Dr. A. P. Barer who carried out the pepsin estimations for this study.

\section{REFERENCES}

1. Bean, W. B., and Hodges, R. E., Pantothenic acid deficiency induced in human subjects. Proc. Soc. Exper. Biol. \& Med., 1954, 86, 693.

2. Bean, W. B., Hodges, R. E., and Daum, K., Pantothenic acid deficiency induced in human subjects. J. Clin. Invest., 1955, 34, 1073.

3. Lipmann, F., Acetylation of sulfanilamide by liver homogenates and extracts. J. Biol. Chem., 1945, 160, 173.

4. Krehl, W. A., Pantothenic acid in nutrition. Nutrition Rev., 1953, 11, 225.

5. Hunt, J. N., The secretory pattern of the stomach of man. J. Physiol., 1951, 113, 169.

6. Hunt, J. N., and Spurrell, W. R., The pattern of emptying of the human stomach. J. Physiol., 1951, 113, 157.

7. Hunt, J. N., The interpretation of fractional test meals : some studies in a "glass stomach." Guy's Hosp. Rep., 1953, 102, 157.

8. Hunt, J. N., The inhibitory action of sucrose on gastric digestive activity in patients with peptic ulcer. Guy's Hosp. Rep., 1954, 103, 161.

9. Penner, A., Hollander, F., and Saltzman, M., The gastric absorption of phenol red in humans. Am. J. Digest. Dis., 1938, 5, 657.

10. Hunt, J. N., An interpretation of histamine and insulin tests in patients with peptic ulceration. Lancet, 1950, 2, 397.

11. Hollander, F., Studies in gastric secretion. IV. Variations in the chlorine content of gastric juice and their significance. J. Biol. Chem., 1932, 97, 585.

12. Ihre, B., Human gastric secretion; a quantitative study of gastric secretion in normal and pathological conditions. Acta med. Scandinav., 1938, Suppl., 95.

13. Haeger, K., Jacobsohn, D., and Kahlson, G., The level of histaminase in thoracic duct lymph as an indicator of adrenocortical activity. Acta physiol. Scandinav., 1953, 30, Supp. 111, p. 170.

14. Bucher, G. R., Grossman, M. I., and Ivy, A. C., A pepsin method: the rôle of dilution in the determination of peptic activity. Gastroenterology, 1945, 5,501 .

15. Orringer, D., Lauber, F. U., and Hollander, F., Use of dried bovine hemoglobin powder in the Anson and Mirsky methods for pepsin and trypsin. Science, 1950, 111, 88.

16. Anson, M. L., The estimation of pepsin, trypsin, papain, and cathepsin with hemoglobin. J. Gen. Physiol., 1938, 22, 79.

17. Wolf, S., Experimental observations on changes in emotional state and physiologic disturbances in the gastrointestinal tract in Postgraduate Gastroenterology. Bockus, H. L., Ed., Philadelphia, Saunders, 1950, p. 225.

18. Krehl, W. A., Winters, R. W., and Schultz, R. B., Adrenal function in pantothenic acid deficiency. Nutrition Symposium Series, National Vitamin Foundation, Inc., 1952, 5, 39.

19. Spiro, H. M., Reinfenstein, R. W., and Gray, S. J., The effect of adrenocorticotrophic hormone upon uropepsin excretion. J. Lab. \& Clin. Med., 1950, 35, 899.

20. Crane, E. E., Davies, R. E., and Longmuir, N. M., Relations between hydrochloric acid secretion and electrical phenomena in frog gastric mucosa. Biochem. J., 1948, 43, 321. 